\title{
Correction to: Lack of netrin-4 alters vascular remodeling in the retina
}

\author{
Sergio Crespo-Garcia ${ }^{1,2,3}$ (D) - Nadine Reichhart ${ }^{1}$ - Jeffrey Wigdahl ${ }^{4}$ - Sergej Skosyrski ${ }^{1}$ • Norbert Kociok ${ }^{1}$. \\ Olaf Strau $\beta^{1}$. Antonia M. Joussen ${ }^{1}$
}

Published online: 15 November 2019

(C) Springer-Verlag GmbH Germany, part of Springer Nature 2019

\section{Correction to: Graefe's Archive for Clinical and \\ Experimental Ophthalmology (2019) 257:2179-2184 \\ https://doi.org/10.1007/s00417-019-04447-3}

The article "Lack of netrin- 4 alters vascular remodeling in the retina", written by Sergio Crespo-Garcia, Nadine Reichhart, Jeffrey Wigdahl, Sergej Skosyrski, Norbert Kociok, Olaf Strauß and Antonia M. Joussen, was originally published Online First with Open Access under a Creative Commons Attribution (CC BY) licence 4.0. After publication in volume 257, issue 10, pages 2179-2184 the author(s) decided to cancel Open Access. Therefore, the copyright of the article has been changed to (C) Springer-Verlag GmbH Germany, part of Springer Nature 2019 with all rights reserved.

The original article has been corrected.

Publisher's note Springer Nature remains neutral with regard to jurisdictional claims in published maps and institutional affiliations.

The online version of the original article can be found at https://oi.org/ 10.1007/s00417-019-04447-3

Sergio Crespo-Garcia

sergiocrespogarcia@gmail.com

1 Experimental Ophthalmology, Department of Ophthalmology,

Charité - Universitätsmedizin Berlin, Freie Universität,

Humboldt-University, the Berlin Institute of Health, Augustenburger, Platz 1, 13353 Berlin, Germany

2 Department of Ophthalmology, Maisonneuve-Rosemont Hospital, Research Centre, Université de Montréal, Montréal, Canada

3 Department of Biochemistry, Maisonneuve-Rosemont Hospital, Research Centre, Université de Montréal, Montréal, Canada

4 VisionQuest Biomedical LLC, Albuquerque, NM, USA 